\title{
C-reactive protein is associated with cigarette smoking-induced hyperfiltration and proteinuria in an apparently healthy population
}

\author{
Rani Sauriasari ${ }^{1}$, Noriko Sakano ${ }^{1}$, Da-Hong Wang ${ }^{1}$, Jiro Takaki ${ }^{1}$, Kei Takemoto ${ }^{1}$, BingLing Wang ${ }^{1}$, \\ Hitoshi Sugiyama $^{2,3}$, Yoshie Sato ${ }^{4}$, Tomoko Takigawa ${ }^{1}$, Noriko Takahashi ${ }^{1}$, Sakiko Kanbara ${ }^{1,5}$, Yoshiaki Hitomi ${ }^{6}$, \\ Hiroyuki Nakamura $^{6}$ and Keiki Ogino ${ }^{1}$
}

Although cigarette smoking is known to be an important risk factor for renal disease, the mechanism by which smoking induces progressive renal disease in a healthy population has not been established. We hypothesized that oxidative stress (measured as 8-iso-prostaglandin $\mathrm{F}_{2 \alpha}$, 8-iso-PGF2a), inflammation (highly sensitive C-reactive protein (CRP), hs-CRP) and nitric oxide may be associated with an alteration in the estimated glomerular filtration rate (eGFR) and proteinuria in otherwise healthy smokers. A total of 649 eligible subjects were classified according to their smoking status. Plasma NOx was measured using ozone-based chemiluminescence, urinary 8-iso-PGF2a was measured using enzyme immunoassay and serum hs-CRP was measured using a latex aggregation nephelometry method. The levels of 8-iso-PGF2a and hs-CRP increased in current smokers $(P=0.001$ and $\boldsymbol{P}=\mathbf{0 . 0 2 9}$, respectively), although there was not an increase in the NOx level. The prevalence of a high eGFR increased in light smokers (odds ratio (OR) 1.15 (95\% confidence interval $(\mathrm{CI}), 0.61-2.17)$ ) and heavy smokers $(\mathrm{OR} 2.33(95 \% \mathrm{Cl}, 1.06-5.10)$ ) when compared with non- and past smokers ( $P$ for trend=0.024). The multivariable-adjusted mean values of the eGFR in current smokers, reported from the lowest to the highest quintiles of hs-CRP levels, were 82.1, 85.1, 86.4 and 88.5 $\mathrm{ml}$ per $\min$ per $1.73 \mathrm{~m}^{2}\left(P\right.$ for trend $=0.027$ ). The mean values of proteinuria were $28.6,34.6,37.2$ and $39.5 \mathrm{mg} \mathrm{g}^{-1} \mathrm{creatinine}$ $(P$ for trend=0.003). The correlation coefficient between hs-CRP and eGFR was increased significantly $(P=0.03)$ across non- $(r=0.03)$, past $(r=-0.17)$, light $(r=0.13)$ and heavy smokers $(r=0.31)$. In conclusion, cigarette smoking is a risk factor for renal function alteration in healthy smokers and is characterized by a high eGFR and a high urinary protein associated with an increase in the hs-CRP. This finding suggests that hs-CRP may help mediate the alteration of renal function in smokers. Hypertension Research (2010) 33, 1129-1136; doi:10.1038/hr.2010.154; published online 12 August 2010

Keywords: cigarette smoking; hs-CRP; nitric oxide; renal function; 8-iso-PGF2a

\section{INTRODUCTION}

Unhealthy lifestyles are presumed to oxidatively or nitrosatively modify cellular constituents, even in the 'preclinical stages of disease,' in biological systems. ${ }^{1,2}$ The measurement of biomarkers of reactive species in biological samples has been suggested to be useful in predicting early disease development in healthy people., ${ }^{3,4}$ Cigarette smoking has been identified as an important risk factor in the promotion and progression of renal dysfunction, not only in subjects with pre-existent primary renal disease, hypertension and diabetes, ${ }^{5-7}$ but also in healthy subjects..$^{8-10}$ Some investigations have raised hypotheses regarding the mechanisms of smoking-induced renal dysfunction, in which nonhemodynamic mechanisms are suggested to be involved in sequential steps of renal glomerulosclerosis and/or atherosclerosis. ${ }^{8}$ Endothelial dysfunction occurs early in renal glomerulosclerosis and/or atherosclerosis and is manifested by an increase in the reactive oxygen species, an elevation of inflammatory factors ${ }^{11}$ or a decrease in the nitric oxide (NO) level. ${ }^{8,12}$

Many studies suggest that cigarette smoking is associated with an augmented progression of renal dysfunction among patients with primary renal disease, hypertension and diabetes, ${ }^{5-7}$ and that increases in both oxidative stress and inflammation may mediate renal dysfunction in hypertensive subjects. ${ }^{13}$ This finding raises a question as to whether similar conditions might arise in healthy subjects who smoke, as to the best of our knowledge, no published research has used

\footnotetext{
${ }^{1}$ Department of Public Health, Okayama University, Graduate School of Medicine, Dentistry and Pharmaceutical Sciences, Okayama, Japan; ${ }^{2}$ Department of Medicine and Clinical Science, Okayama University, Graduate School of Medicine, Dentistry and Pharmaceutical Sciences, Okayama, Japan; ${ }^{3}$ Center for Chronic Kidney Disease and Peritoneal Dialysis, Okayama University, Graduate School of Medicine, Dentistry and Pharmaceutical Sciences, Okayama, Japan; ${ }^{4}$ Department of Nursing, Okayama University, Graduate School of Health Sciences, Okayama, Japan; ${ }^{5}$ University of KinDai Himeji, School of Nursing, Himeji, Japan and ${ }^{6}$ Department of Environmental and Preventive Medicine, Kanazawa University, Graduate School of Medical Science, Kanazawa, Japan

Correspondence: Professor K Ogino, Department of Public Health, Okayama University, Graduate School of Medicine, Dentistry and Pharmaceutical Sciences, Kita-ku Shikata-cho 2-5-1, Okayama 700-8558, Japan.

E-mail: kogino@md.okayama-u.ac.jp
}

Received 28 April 2010; revised 24 May 2010; accepted 6 June 2010; published online 12 August 2010 
oxidative stress and inflammatory markers to assess the mechanism by which cigarette smoking induces progressive renal dysfunction in the general population.

Cigarette smoke contains abundant reactive oxygen species; the particulate (tar) phase of cigarette smoke contains $>10^{17}$ free radicals per $\mathrm{g}$, and the gas phase contains $>10^{15}$ free radicals per puff. ${ }^{14}$ One of the most tested and generally evaluated biomarkers of systemic oxidative stress is 8-iso-prostaglandin $\mathrm{F}_{2 \alpha}$ (8-iso-PGF2a), which is the major urinary metabolite of the $\mathrm{F}_{2}$-isoprostane series. ${ }^{15}$

C-reactive protein (CRP) is a circulating pentraxin that has a major role in the human innate immune response. Highly sensitive CRP (hs-CRP) is considered to be a stable plasma biomarker for low-grade systemic inflammation. ${ }^{16}$ Although CRP is produced predominantly in the liver, it is also expressed in smooth muscle cells and has a central role in all phases of the atherosclerotic process. ${ }^{1,16,17}$

NO, the mediator of endothelium-dependent relaxation, is produced by the oxidation of L-arginine in an enzymatic reaction catalyzed by nitric oxide synthase. Although the measurement of $\mathrm{NO}$ itself cannot be performed, nitrite $\left(\mathrm{NO}_{2}{ }^{-}\right)$and nitrate $\left(\mathrm{NO}_{3}{ }^{-}\right)$ (NOx) are commonly used as an index of systemic NO formation in many studies, based on the finding that NOx is the main stable metabolite. ${ }^{18}$ This study is the first attempt to employ an ozone-based chemiluminescence assay for detecting plasma NOx in a large, healthy population.

As for the assessment of renal function, we calculated the estimated glomerular filtration rate (eGFR), measured protein urine, serum creatinine (Cre), blood urea nitrogen and uric acid. Because the GFR estimation is limited by differences in Cre generation among ethnicities, we calculated eGFR using an equation specific to the Japanese that was recently released by the Japanese Society of Nephrology. ${ }^{19}$

We hypothesized that 8-iso-PGF2a, hs-CRP, and/or NO probably contribute to the mediation of renal function alteration in smokers. We therefore investigated the cross-sectional associations between smoking-related markers (8-iso-PGF2a, CRP and NOx) and eGFR and proteinuria in the general population, while considering the effect of potential confounders, such as lifestyle choices.

\section{METHODS}

\section{Study design}

A cross-sectional study on the relationship between oxidative/nitrosative biomarkers and lifestyle-related disease was designed within the framework of a laboratory and field study. We performed health examinations and surveys of 847 Japanese individuals from September to December 2007. All subjects were instructed to fast overnight and refrain from smoking beginning at least $10 \mathrm{~h}$ before the sample collection. The ethics committee of Okayama University approved the study, and written informed consent was obtained from each subject before participation.

\section{Collection of samples}

Venous blood samples were collected after overnight fasting. Serum and plasma were preserved at $-80^{\circ} \mathrm{C}$ until analysis. Some of the biochemical parameters of the blood samples were analyzed in Mitsubishi Chemical Medience Laboratory (Tokyo, Japan). This laboratory meets the standards of ISO 15189, the international quality management standard for laboratory testing in Japan. The blood pressure of each subject was measured by a physician with the subject in a sitting position after resting for at least a few minutes. Information on lifestyle factors was obtained through self-reporting on questionnaires. Smoking status was classified into three categories: nonsmokers, past smokers and current smokers. For subgroup analysis, current smokers were classified into two groups based on the pack-year unit: light smokers had a smoking history of $<20$ pack-years; and heavy smokers had a smoking history of $\geqslant 20$ pack-years. A pack-year is equal to
20 cigarettes ( 1 pack), or the equivalent, smoked per day for 1 year. Alcohol consumption was converted into number of units per week. One unit was considered to be equivalent to $9-12 \mathrm{~g}$ of ethanol. Exercise was defined as no exercise, 1-3 times per week or more than 4 times per week.

Exclusion criteria included a history of cancer, stroke, diabetes, hypertension, ischemic heart disease, hepatitis or asthma. We also excluded women who were pregnant, breast-feeding or menstruating. Data from a total of 649 volunteers (age 18-67 years) were ultimately analyzed.

\section{Analysis of oxidative/nitrosative stress and inflammation biomarkers}

Urinary 8-iso-PGF2a level was determined by analyzing spot urine samples stored at $-80^{\circ} \mathrm{C}$ before analysis, using a commercially available competitive enzyme immunoassay (EIA) kit (Cayman Chemical, Ann Arbor, MI, USA). The samples were corrected for Cre excretion. Helmersson and Basu ${ }^{20}$ reported that urinary $\mathrm{F}_{2}$-isoprostanes isomer levels in spot urine samples showed no significant variation from levels measured in 24-h urine samples in the same healthy individuals by radioimmunoassay. hs-CRP level was determined using a latex particle-enhanced immunoassay with the nephelometry method. The assay was able to detect $0.004-0.500 \mathrm{mg}$ per $100 \mathrm{ml}$ of CRP.

NO level was determined using an ozone-based chemiluminescence assay. ${ }^{21}$ We used a freshly prepared reductive chemical, triiodide $\left(\mathrm{I}_{3}^{-}\right)$, as described in a previous study. ${ }^{22}$ To minimize protein foaming, $100 \mu \mathrm{l}$ of 1:30 diluted silicon emulsion was added. The reduction of $\mathrm{NO}_{3}{ }^{-}$to $\mathrm{NO}_{2}{ }^{-}$was performed by incubation with $25 \mathrm{mU} \mathrm{NO}_{3}{ }^{-}$reductase enzyme (EC 1.7.1.2, Sigma, Tokyo, Japan) solution mixed with $0.012 \mu \mathrm{mol}$ of the cofactor $\beta$-nicotinamide adenine dinucleotide phosphate. A standard curve relating the luminescence produced was constructed by injecting freshly prepared commercial $\mathrm{NO}_{3}{ }^{-}$standard solution (WAKO, Osaka, Japan) into NO analyzer (Sievers, NOA280i, Boulder, CO, USA). Plasma was prepared in a similar manner with standard solution. To ensure accurate analysis, we took care in sample collection, minimized light exposure and used distilled water with no $\mathrm{NO}_{2}{ }^{-}$content (Otsuka Pharmaceutical, Tokyo, Japan).

\section{Measurement of renal function}

We calculated eGFR using an equation specific to the Japanese population that was recently released by the Japanese Society of Nephrology: ${ }^{19}$

$$
\text { eGFR }=194 \times \text { serum Cre }{ }^{-1.094} \times \text { age }^{-0.287}(\times 0.739 \text { if female })
$$

The serum Cre and uric acid levels were measured enzymatically, whereas the Bradford method (Bio-Rad Protein Assay Kit, Bio-Rad, Hercules, CA, USA) with bovine serum albumin (BSA) as a calibrator was used to measure the urinary protein content. Briefly, in a 96-well plate, the protein calibrator (10 $\mu$ l of bovine serum albumin $0,31.25,62.5,125,250$ and $500 \mu \mathrm{g} \mathrm{m}^{-1}$ ) or $10 \mu \mathrm{l}$ urine were mixed with $200 \mu \mathrm{l}$ of protein assay solution diluted with four volumes of ultrapure water. After $5 \mathrm{~min}$, we measured the absorbance of the assay mixture at $595 \mathrm{~nm}$ using a microplate reader (Molecular Devices VersaMax, Sunnyvale, CA, USA). The urine Cre concentration was determined in single spot urine samples using creatinine test kits (R\&D Systems, Minneapolis, MN, USA). Urinary protein was defined as the urine protein/Cre ratio $\left(\mathrm{mg} \mathrm{g}^{-1}\right)$.

The blood urea nitrogen level was determined using the urease-indophenol method (WAKO), in which urea is hydrolyzed by urease to produce ammonia and $\mathrm{CO}_{2}$ (WAKO). The ammonia reacts with the salicylate and hypochlorite in the presence of the catalyst nitroprusside to form a green indophenol in alkaline solution. The amount of urea nitrogen in the sample was determined by measuring the absorbance at $570 \mathrm{~nm}$.

\section{Statistical analysis}

After the outliers were excluded, we transformed the skewed distributed variables (body mass index, NOx, 8-iso-PGF2a, hs-CRP, triglyceride, glucose, aspartate aminotransferase, $\gamma$-glutamyl transpeptidase and protein urine) into $\log _{10}$ format. The data were expressed as a percentage, the arithmetic mean (antilog for $\log _{10}$-transformed data) \pm s.d./s.e. or an odds ratio (OR) (95\% CI). Because the differences between the smoking groups in terms of the biochemical parameters could have been confounded by age, sex and body mass index, we analyzed our data using analysis of covariance by adjusting for those potential confounders. After conducting multicollinearity diagnostics among 
the independent variables, we performed a binomial logistic regression analysis to evaluate the independent relationship between smoking with eGFR and smoking with markers. The test for a linear trend across mean values and ORs of hs-CRP quartiles, 8-iso-PGF2a quartiles or smoking status was conducted by means of orthogonal polynomial contrast. Bivariate correlations between renal function parameters with markers, while controlling other variables, were determined using partial correlation. For comparing the correlation coefficient $(r)$, we transformed $r$ with the Fisher- $z$ transform equation to the $Z$-score. We then calculated a $Z$-score of the differences between the correlations to determine the level of significance as follows: ${ }^{23}$

$$
Z_{\text {differences }}=\frac{Z r_{1}-Z r_{2}}{\sqrt{ } 1 / n_{1}-3+1 / n_{2}-3}
$$

where $r=$ correlation coefficient and $n=$ number of subjects.

Data analyses were performed using SPSS software (SPSS, Chicago, IL, USA; Version 12). A value of $P<0.05$ was considered to be statistically significant.

\section{RESULTS}

This study population included 290 men and 359 women (18-67 years old). Table 1 shows the mean urinary 8 -iso-PGF2a to be $0.7 \pm 2.1 \mathrm{ng} \mathrm{mg}^{-1}$ Cre in men and $0.5 \pm 2.5 \mathrm{ng} \mathrm{mg}^{-1}$ Cre in women. The intra- and inter-assay repeatability (percent coefficient of variation) were 5.4 and $11.0 \%$, respectively. The mean of the hs-CRP level was $0.06 \pm 0.08 \mathrm{mg}$ per $100 \mathrm{ml}$ in men and $0.05 \pm 0.08 \mathrm{mg}$ per $100 \mathrm{ml}$ in women. The $\mathrm{NO}_{3}{ }^{-}$standard slope was $y=1.60 x-18.13$ $\left(r^{2}=0.9974\right)$, and the mean plasma NOx concentration was $27.5 \pm 1.6 \mu \mathrm{moll}^{-1}$ in men and $24.0 \pm 1.6 \mu \mathrm{moll}^{-1}$ in women. The intra- and inter-assay repeatability over 2 months were 3.5 and $6.1 \%$, respectively. These values are very similar to or within the range of many other population studied. ${ }^{24,25}$ A high eGFR was defined as in the upper $20 \%$ or the highest quintile $\left(\geqslant 96.7 \mathrm{ml}\right.$ per min per $\left.1.73 \mathrm{~m}^{2}\right)$, and, similarly, high urinary protein was defined as the highest quintile $\left(\geqslant 49.4 \mathrm{mg} \mathrm{g}^{-1}\right.$ Cre $)$.

\section{Table 1 Characteristics of study subjects}

\begin{tabular}{|c|c|c|}
\hline & Male (290) & Female (359) \\
\hline Age & $41.0 \pm 9.9$ & $42.2 \pm 10.9$ \\
\hline \multicolumn{3}{|l|}{ Anthropometric parameters } \\
\hline Weight (kg) & $68.1 \pm 10.1$ & $53.8 \pm 9.3$ \\
\hline Height $(\mathrm{cm})$ & $170.2 \pm 5.5$ & $157.4 \pm 5.3$ \\
\hline Waist circumference $(\mathrm{cm})$ & $83.7 \pm 8.9$ & $76.5 \pm 10.1$ \\
\hline $\mathrm{BMI}\left(\mathrm{kg} \mathrm{m}^{-2}\right)$ & $23.3 \pm 1.1$ & $21.5 \pm 1.2$ \\
\hline \multicolumn{3}{|l|}{ Lifestyle } \\
\hline \multicolumn{3}{|l|}{ Smoking } \\
\hline Smoking duration (years) & $11.8 \pm 12.4$ & $2.7 \pm 7.1$ \\
\hline Smoking amount (cigarettes per day) & $20.3 \pm 8.4$ & $14.3 \pm 8.2$ \\
\hline Alcohol consumption (units per week) & $6.2 \pm 7.3$ & $1.9 \pm 3.7$ \\
\hline \multicolumn{3}{|l|}{ Exercise $(n(\%))$} \\
\hline No exercise & $122(42)$ & $235(66)$ \\
\hline 1-3 times per week & $105(36)$ & $87(24)$ \\
\hline 4 or more times per week & $63(22)$ & $37(10)$ \\
\hline
\end{tabular}

Marker

\begin{tabular}{|c|c|c|}
\hline 8-iso-PGF2a (ng mg ${ }^{-1}$ Cre) & $0.7 \pm 2.1$ & $0.5 \pm 2.5$ \\
\hline High-sensitivity CRP (mg per $100 \mathrm{ml}$ ) & $0.06 \pm 0.08$ & $0.05 \pm 0.08$ \\
\hline $\mathrm{NOx}\left(\mu \mathrm{mol} \mathrm{I}^{-1}\right)$ & $27.5 \pm 1.6$ & $24.0 \pm 1.6$ \\
\hline
\end{tabular}

Abbreviations: BMI, body mass index; CRP, C-reactive protein.

Data are shown as mean \pm s.d. Skewed data were $\log 10$-transformed and presented as mean value converted into exponential.
As Table 2 shows, the age, sex and body mass index adjusted mean values of 8 -iso-PGF2a and hs-CRP were significantly increased in current smokers in comparison with non- and past smokers $\left(0.7 \pm 1.07\right.$ vs. $0.5 \pm 1.04$ and $0.5 \pm 1.12 \mathrm{ng} \mathrm{mg}^{-1}$ Cre for 8 -iso-PGF2a; $0.07 \pm 0.006$ vs. $0.05 \pm 0.004$ and $0.04 \pm 0.010 \mathrm{mg}$ per $100 \mathrm{ml}$ for hsCRP). However, the NOx level did not differ among the smoking groups. The urinary protein content was higher in current smokers $\left(37.0 \pm 1.04\right.$ vs. $35.5 \pm 1.02$ and $\left.31.1 \pm 1.06 \mathrm{mg} \mathrm{g}^{-1} \mathrm{Cre}\right)$, whereas the serum Cre decreased significantly $(0.70 \pm 0.008$ vs. $0.72 \pm 0.005$ and $0.73 \pm 0.013 \mathrm{mg}$ per $100 \mathrm{ml}$ ). Moreover, smokers showed significant changes in the systolic blood pressure, diastolic blood pressure and blood profile (total protein, white blood cell and hemoglobin), in addition to increased $\gamma$-glutamyl transpeptidase and triglycerides.

A logistic regression analysis with adjustment for demographic, physical and clinical variables showed that the prevalence of a high eGFR increased in current smokers in a dose-dependent manner $(\mathrm{OR}=1.24(95 \% \mathrm{CI}, 0.66-2.31)$ for light smokers; $\mathrm{OR}=2.68(95 \%$ CI, 1.27-5.66) for heavy smokers ( $P$ for trend 0.006)). Adjusting for lifestyle variables (alcohol consumption and exercise) further attenuated the prevalence of a high eGFR, and the OR was still found to be significant $(\mathrm{OR}=1.14$ (95\% CI, 0.61-2.15) for light smokers; OR $=2.33(95 \% \mathrm{CI}, 1.07-5.11)$ for heavy smokers ( $P$ for trend 0.024)) (Table 3).

As Table 4 shows, the mean values and ORs of high eGFR according to 8-iso-PGF2a quartiles were significant for nonsmokers, but not for current smokers. On the other hand, the increase in the hs-CRP level was in parallel with the increase of eGFR and the urinary protein level, which was observed only in current smokers, but not in nonsmokers (Table 5). The mean values from the lowest to highest quartile of hs-CRP in current smokers were 82.1, 85.2, 86.4 and 88.5 for eGFR $(P$ for trend $=0.027)$ and $28.6,34.6,37.2$ and 39.5 for urinary protein ( $P$ for trend $=0.003$ ). Meanwhile, the prevalence of a high eGFR also increased with an increase in the hs-CRP levels. We did not show data of past smokers because there was not a prevalence of a high eGFR for some groups in the hs-CRP and 8-isoprostane quartiles of past smokers.

After conducting a partial correlation test, we found that the eGFR of current smokers was positively correlated with hs-CRP ( $r=0.16$, $P=0.033$ ). When the group of current smokers was stratified to light and heavy smokers, the Fisher- $z$ transformation test showed a significant increase $(P=0.032)$ across non- $(r=0.03)$, past $(r=-0.17)$, light $(r=0.13)$ and heavy smokers $(r=0.31)$. Testing to determine whether one correlation coefficient is higher than another showed that the correlation between hs-CRP and eGFR in heavy smokers was higher than nonsmokers $(P=0.023)$ and past smokers $(P=0.008)$ (Figure 1).

\section{DISCUSSION}

This study demonstrates that cigarette smokers have an alteration in renal function characterized by a higher eGFR/hyperfiltration and higher urinary protein levels, which is consistent with other studies conducted in humans ${ }^{9,26}$ and animals. ${ }^{27}$ Previously, Pinto-Sietsma et al. $^{28}$ demonstrated a relationship between smoking and either an increased or decreased GFR in the same population. On the other hand, some studies reported contradictory findings that cigarette smoking reduced GFR. ${ }^{29,30}$ It was suggested by Yoon et al. ${ }^{9}$ that smoking is associated with an increase in eGFR, although a different impact might be presented for a small subset of the population who were more susceptible to a decrease in eGFR.

Two previous studies did not take other lifestyle factors (alcohol consumption and exercise) into account, ${ }^{9,26}$ but our study showed 
Table 2 Age, sex and BMI-adjusted clinical characteristics of study subjects according to the smoking status

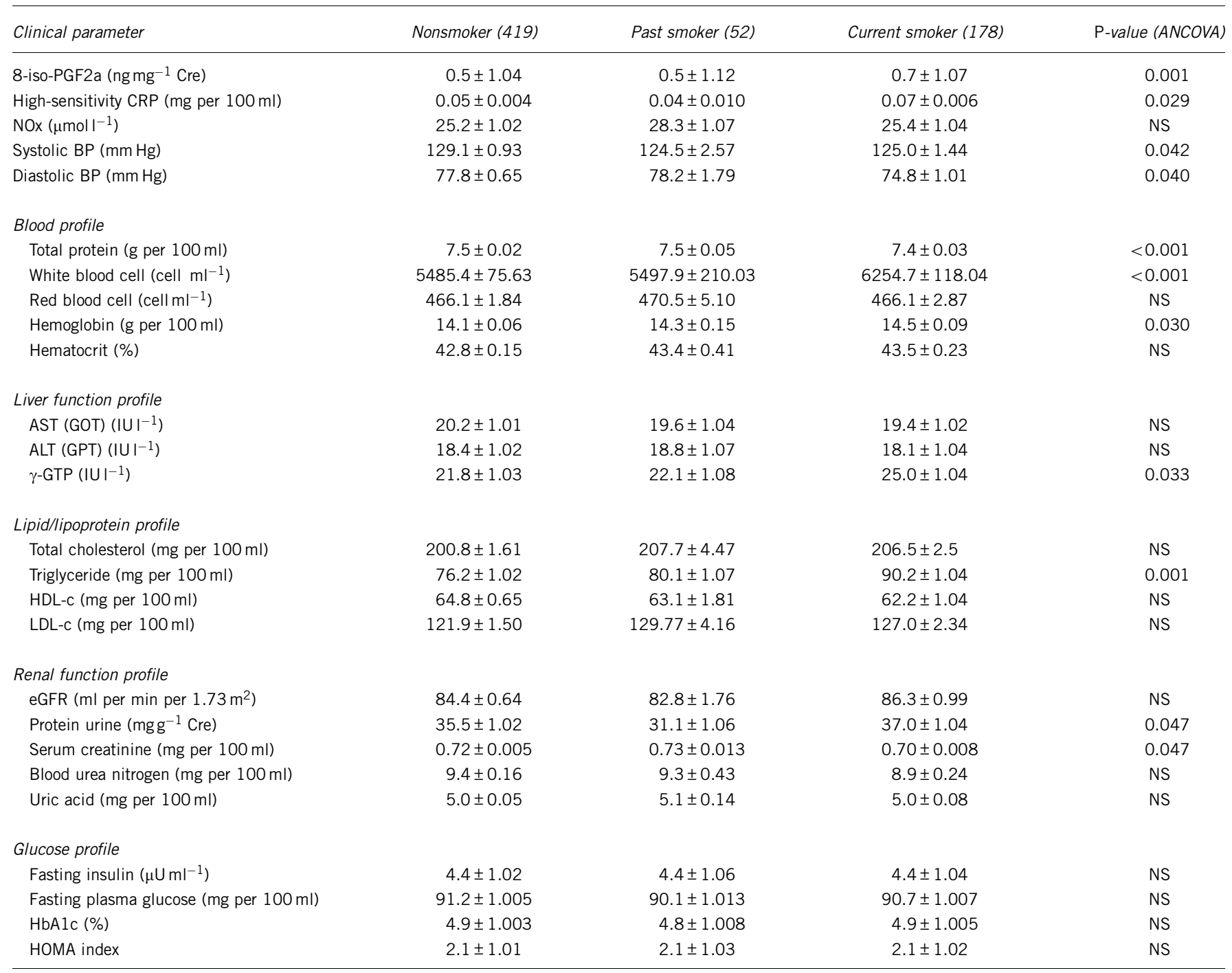

Abbreviations: ALT, alanine transaminase; ANOVA, analysis of variance; AST, aspartate aminotransferase; BMI, body mass index; BP, blood pressure; CRP, C-reactive protein; eGFR, estimated glomerular filtration rate; $\gamma$-GTP, $\gamma$-glutamyl transpeptidase; HbA1c, hemoglobin Alc; HDL-c, high-density lipoprotein-cholesterol; HOMA, homeostatic model assessment; LDL-c, low-density

lipoprotein-cholesterol; NS, nonsignificant.
Data are shown as mean \pm s.e. Skewed data were $\log _{10}$-transformed and presented as mean value converted into exponential age, sex and BMI adjusted. eGFR=194Cr-1.094 $\times$ age ${ }^{-0.287} \times 0.739$ (if female).

that these two factors confounded the results. An increasing alcohol consumption $^{31}$ and intensity of daily physical exercise ${ }^{32}$ correlated with the increase of GFR. However, smoking strongly and independently increased eGFR because the significance persists even after controlling for alcohol consumption and exercise.

Evidence of thickening of the walls of the renal arterioles and small arteries after nicotine abuse has been found during autopsies of patients with renal disease ${ }^{33}$ and subjects without known renal or vascular disease. ${ }^{34}$ Moreover, animal experimental evidence indicates that cigarette smoking enhanced the permeability of the endothelial monolayers ${ }^{35}$ and an elevation of intraglomerular capillary pressure, which is associated with an elevated GFR. It was reported that there is an association between an elevated GFR and a high-normal albuminuria in the nondiabetic population. ${ }^{36}$ Many other studies also have documented an increased risk of proteinuria in smokers. ${ }^{9,10,26,28}$ Here we observed that current smokers have a higher urinary protein level than non- and past smokers. Certain drugs, such as angiotensin II receptor blockers, may affect the amount of urinary protein excretion. However, our study subjects are an apparently healthy population who do not consume any other medications, including angiotensin II receptor blockers.

The mechanism of this higher renal function in current smokers is still unknown. It was hypothesized that cigarette smoke eventually causes renal vasodilation, leading to chronic glomerular hyperfiltration mediated by an increased urinary cyclic guanosine monophosphate, and release of $\mathrm{NO}$ and atrial natriuretic peptide. ${ }^{10}$ However, the plasma NOx concentration was not associated with smoking status in our present study population. In vitro and in vivo studies showed a reduction of NO after cigarette smoking exposure. ${ }^{37-39}$ However, the majority of in vitro data has involved the use of cigarette smoke extract solution, which is probably not an appropriate physiological model, as circulating particulate of cigarette smoke has to first bypass the lung. ${ }^{40}$ Thus, the effect of smoking on the NO pathway seems to be more complex on a cellular level than suggested by the described 
Table 3 Odds ratio of high eFGR and high protein/creatinine urine ratio according to the smoking status

\begin{tabular}{|c|c|c|c|c|c|}
\hline & \multirow[b]{2}{*}{ Nonsmoker } & \multirow[b]{2}{*}{ Past smoker } & \multicolumn{2}{|c|}{ Current smoker } & \multirow[b]{2}{*}{ P for trend } \\
\hline & & & Light smoker & Heavy smoker & \\
\hline Model $1^{a}$ & 1.00 & $0.65(0.23-1.83)$ & $1.06(0.59-1.97)$ & $2.32(1.15-4.81)^{*}$ & \\
\hline Model $2^{\mathrm{b}}$ & 1.00 & $0.67(0.24-1.90)$ & $1.08(0.59-1.98)$ & $2.38(1.15-4.93)^{*}$ & \\
\hline Model $3^{c}$ & 1.00 & $0.72(0.26-2.03)$ & $1.24(0.66-2.31)$ & $2.68(1.27-5.66)^{*}$ & \\
\hline \multicolumn{6}{|c|}{ High protein urine $\left(\geqslant 49.4 \mathrm{mgg}^{-1} \mathrm{Cre}\right)$} \\
\hline Model $1^{a}$ & 1.00 & $0.70(0.29-1.66)$ & $1.08(0.58-2.02)$ & $1.38(0.71-2.67)$ & \\
\hline Model $2^{b}$ & 1.00 & $0.73(0.30-1.77)$ & $1.17(0.63-2.20)$ & $1.56(0.79-3.09)$ & \\
\hline Model $3^{c}$ & 1.00 & $0.73(0.30-1.77)$ & $1.12(0.59-2.14)$ & $1.38(0.68-2.80)$ & \\
\hline Model $4^{\mathrm{d}}$ & 1.00 & $0.73(0.30-1.79)$ & $1.10(0.58-2.12)$ & $1.36(0.65-2.81)$ & 0.274 \\
\hline
\end{tabular}

Table 4 Multivariable-adjusted mean values of eGFR or protein urine and odds ratio of high eGFR or high protein/creatinine urine ratio according to quartiles of 8-iso-PGF2a stratified by smoking status

\begin{tabular}{|c|c|c|c|c|c|}
\hline & \multicolumn{4}{|c|}{ Quartiles of 8-iso-PGF2a concentrations } & \multirow[b]{2}{*}{$\mathrm{P}$ for trend } \\
\hline & Q1 & Q2 & Q3 & Q4 & \\
\hline \multicolumn{6}{|l|}{ Nonsmoker } \\
\hline eGFR, mean & $82.3 \pm 1.1$ & $85.6 \pm 1.2$ & $86.6 \pm 1.3$ & $86.2 \pm 1.5$ & 0.037 \\
\hline Odds ratio for high eGFR & 1.00 & $2.64(1.17-5.97)^{*}$ & $2.22(0.94-5.23)$ & $3.07(1.30-7.25)^{*}$ & 0.021 \\
\hline \multicolumn{6}{|l|}{ Current smoker, number } \\
\hline eGFR, mean & $84.8 \pm 2.7$ & $82.8 \pm 2.2$ & $84.9 \pm 1.6$ & $88.0 \pm 1.4$ & 0.227 \\
\hline Odds ratio for high eGFR & 1.00 & $0.54(0.10-2.78)$ & $1.01(0.25-4.11)$ & $1.59(0.41-6.09)$ & 0.360 \\
\hline \multicolumn{6}{|l|}{ Nonsmoker, number } \\
\hline Protein urine, mean & $35.9 \pm 1.0$ & $37.0 \pm 1.0$ & $36.3 \pm 1.0$ & $35.6 \pm 1.1$ & 0.835 \\
\hline Odds ratio for high protein urine & 1.00 & $1.71(.91-3.24)$ & $1.31(0.64-2.68)$ & $1.06(0.47-2.40)$ & 0.939 \\
\hline \multicolumn{6}{|l|}{ Current smoker, number } \\
\hline Protein urine, mean & $34.1 \pm 1.1$ & $31.4 \pm 1.1$ & $36.6 \pm 1.1$ & $36.4 \pm 1.1$ & 0.360 \\
\hline Odds ratio for high protein urine & 1.00 & $1.04(0.22-0.49)$ & $0.86(0.21-3.49)$ & $0.91(0.24-3.45)$ & 0.823 \\
\hline
\end{tabular}

mechanisms. ${ }^{41}$ Recent clinical epidemiological studies in humans showed that the plasma NOx level was a little higher in smokers than in nonsmokers. ${ }^{25,42}$ However, the difference was no longer significant after correction for some important clinical variables. ${ }^{42}$ Moreover, Barua et al. ${ }^{40}$ and Rångemark and Wennmalm ${ }^{43}$ reported no differences in the NOx level among smoking groups, which is similar to our findings. ${ }^{39,43}$

Cigarette smoking generates $\mathrm{O}_{2}^{--}$which contributes to the catalysis of arachidonic acid peroxidation to $\mathrm{F}_{2}$-isoprostanes, leading to a high level of $\mathrm{F}_{2}$-isoprostanes in smokers, as shown in this study and other studies. ${ }^{44,45}$ We did not find a correlation between 8 -iso-PGF2a and either the eGFR or urinary protein in apparently healthy smokers. On the other hand, we detected a positive association between the eGFR and 8-iso-PGF2a only in nonsmokers, although the significance was not present in current smokers. These results indicate that smoking may influence the association between eGFR and 8-iso-PGF2a.

In contrast, we demonstrated a significant association between the hs-CRP and a high eGFR and high urinary protein in current smokers, which was not seen in nonsmokers. Cigarette smoking is known to increase the expression of inflammatory markers, including CRP. ${ }^{11,46}$ This finding indicates that hs-CRP was increased by smoking, and its association with the eGFR and urinary protein was strongly modified by cigarette smoking.

There is an association between proteinuria and vascular permeability, because capillary fluid permeability and transvascular albumin leakage increased in otherwise healthy patients with proteinuria. ${ }^{47}$ 
Table 5 Multivariable-adjusted mean values of eGFR or protein urine and odds ratio of high eGFR or high protein/creatinine urine ratio according to quartiles of highly sensitive C-reactive protein (hs-CRP) stratified by smoking status

\begin{tabular}{|c|c|c|c|c|c|}
\hline & \multicolumn{4}{|c|}{ Quartiles of hs-CRP concentrations } & \multirow[b]{2}{*}{ P for trend } \\
\hline & Q1 & Q2 & Q3 & Q4 & \\
\hline \multicolumn{6}{|l|}{ Nonsmoker } \\
\hline eGFR, mean & $84.6 \pm 1.3$ & $86.4 \pm 1.3$ & $83.4 \pm 1.3$ & $85.2 \pm 1.4$ & 0.856 \\
\hline Odds ratio for high eGFR & 1.00 & $1.96(0.87-4.41)$ & $0.97(0.40-2.34)$ & $1.15(0.44-3.02)$ & 0.461 \\
\hline \multicolumn{6}{|l|}{ Current smoker, number } \\
\hline eGFR, mean & $82.1 \pm 2.1$ & $85.1 \pm 2.0$ & $86.4 \pm 1.6$ & $88.5 \pm 1.8$ & 0.027 \\
\hline Odds ratio for high eGFR & 1.00 & $2.67(0.61-11.66)$ & $2.44(0.56-10.60)$ & $6.27(1.5-26.18)^{*}$ & 0.009 \\
\hline \multicolumn{6}{|l|}{ Nonsmoker, number } \\
\hline Protein urine, mean & $37.2 \pm 1.0$ & $33.7 \pm 1.0$ & $37.7 \pm 1.0$ & $36.4 \pm 1.0$ & 0.859 \\
\hline Odds ratio for high protein urine & 1.00 & $0.82(0.39-1.72)$ & $1.30(0.63-2.71)$ & $0.98(0.45-2.19)$ & 0.735 \\
\hline \multicolumn{6}{|l|}{ Current smoker, number } \\
\hline Protein urine, mean & $28.6 \pm 1.1$ & $34.6 \pm 1.1$ & $37.2 \pm 1.1$ & $39.5 \pm 1.1$ & 0.003 \\
\hline Odds ratio for high protein urine & 1.00 & $3.61(0.75-17.33)$ & $5.63(1.27-24.84)^{*}$ & $4.05(0.88-18.66)$ & 0.109 \\
\hline
\end{tabular}
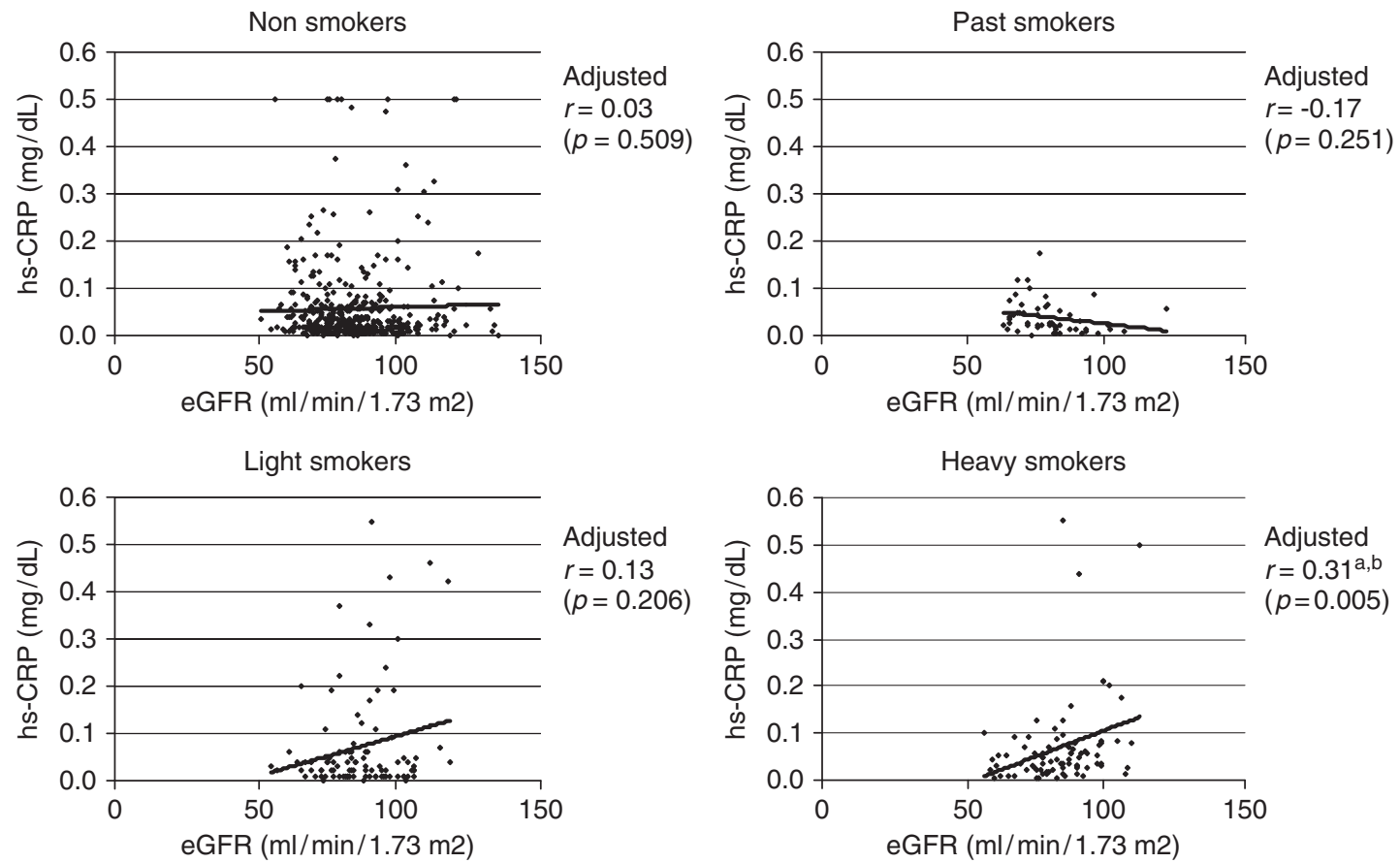

Figure 1 Scatter plot for the correlation between estimated glomerular filtration rate (eGFR) and highly sensitive C-reactive protein (hs-CRP), stratified by smoking status. Adjusted $r$ was adjusted for age, sex and body mass index.

${ }^{\mathrm{a}} P=0.023$ compared with nonsmokers, ${ }^{\mathrm{b}} P=0.008$ compared with past smokers.

One possible mechanism of this increased vascular permeability is endothelial dysfunction. ${ }^{47}$ Given that systemic inflammation at a lowgrade level is held partly responsible for the modulation of vascular permeability, ${ }^{47}$ it is plausible that an elevated CRP derived from cigarette smoking may directly alter renal vascular permeability, and thus be causally involved in the hyperfiltration of remnant glomeruli, resulting in the development of proteinuria. This hyperfiltration, together with the transvascular albumin leakage, could result in further glomerular damage.

The strengths of our study include the population-based samples, the measurement of all clinical variables and biomarkers at a single laboratory using the same evaluation protocols, and the availability of information on potential confounding factors. We measured GFR using a newly derived Cre-based GFR-estimating equation, which 
provided reasonably more accurate and specific eGFR for Japanese individuals. ${ }^{19}$ Moreover, we used a hs-CRP assay, which has high analytical precision. The increased variance of our CRP data yields greater statistical power to detect small, but nonetheless important associations. Potential limitations of this study include a single ethnic origin of participants, which might limit the generalization of the results. The cross-sectional nature of study design also could hardly determine a causal relation between smoking and renal dysfunction. We also could not exclude other potential confounders, such as $\mathrm{NO}_{2}{ }^{-}$ and $\mathrm{NO}_{3}{ }^{-}$intake from drinking water, although water supplied in the Okayama city area contains relatively low levels of $\mathrm{NO}_{2}{ }^{-}$and $\mathrm{NO}_{3}{ }^{-}$ $\left(<0.7 \mathrm{mg} \mathrm{l}^{-1}\right)$, according to the data from the Okayama Water Works Bureau.

In conclusion, we demonstrate here that cigarette smoking was a risk factor for the alteration of renal function, as characterized by a high eGFR and high urinary protein level. This effect may be mediated in part by an increase in the hs-CRP level. Further investigation using a longitudinal study and a larger population study is necessary to confirm the possible clinical implication of this present result.

\section{CONFLICT OF INTEREST}

The authors declare no conflict of interest.

\section{ACKNOWLEDGEMENTS}

This work was supported in part by funding from the Junpukai and in part from the Health Science Center Foundation. We gratefully appreciate technical contributions from A Minoura, S Hamanishi and A Ohashi.

1 Halliwell B, Gutteridge JMC. Cellular responses to oxidative stress: adaptation, damage, repair, senescence and death. In: Halliwell B, Gutteridge JMC (eds). Free Radicals in Biology and Medicine, 4th edn. Oxford University Press: New York, 2007, pp 187-267.

2 Bonassi S, Au WW. Biomarkers in molecular epidemiology studies for health risk prediction. Mutat Res 2002; 511: 73-86.

3 Kimura S, Yamauchi H, Hibino Y, Iwamoto M, Sera K, Ogino K. Evaluation of urinary 8hydroxydeoxyguanine in healthy Japanese people. Basic Clin Pharmacol Toxicol 2006; 98: 496-502.

4 Sakano N, Wang DH, Takahashi N, Wang BL, Sauriasari R, Kanbara S, Sato Y, Takigawa T, Takaki J, Ogino K. Oxidative stress biomarkers and lifestyles in Japanese healthy people. J Clin Biochem Nutr 2009; 44: 185-195.

5 Stegmayr BG. A study of patients with diabetes mellitus (type 1) and end-stage renal failure: tobacco usage may increase risk of nephropathy and death. J Intern Med 1990; 228: $121-124$

6 Orth SR, Stockmann A, Conradt C, Ritz E, Ferro M, Kreusser W, Piccoli G, Rambausek M, Roccatello D, Schafer K, Sieberth HG, Wanner C, Watschinger B, Zucchelli P. Smoking as a risk factor for end-stage renal failure in men with primary renal disease. Kidney Int 1998; 54: 926-931.

7 Regalado M, Yang S, Wesson DE. Cigarette smoking is associated with augmented progression of renal insufficiency in severe essential hypertension. Am J Kidney Dis 2000; 35: 687-694.

8 Orth SR, Hallan SI. Smoking: a risk factor for progression of chronic kidney disease and for cardiovascular morbidity and mortality in renal patients-absence of evidence or evidence of absence? Clin J Am Soc Nephrol 2008; 3: 226-236.

9 Yoon H, Park M, Yoon H, Son K, Cho B, Kim S. The differential effect of cigarette smoking on glomerular filtration rate and proteinuria in an apparently healthy population. Hypertens Res 2009; 32: 214-219.

10 Halimi JM, Giraudeau B, Vol S, Cacès E, Nivet H, Lebranchu Y, Tichet J. Effects of current smoking and smoking discontinuation on renal function and proteinuria in the general population. Kidney Int 2000; 58: 1285-1292.

11 Stuveling EM, Hillege HL, Bakker SJ, Gans RO, De Jong PE, De Zeeuw D. C-reactive protein is associated with renal function abnormalities in a non-diabetic population. Kidney Int 2003; 63: 654-661.

12 Mercado J, Jaimes EA. Cigarette smoking as a risk factor for atherosclerosis and renal disease: novel pathogenic insights. Curr Hypertens Rep 2007; 9: 66-72.

13 Cottone S, Mulè G, Guarneri M, Palermo A, Lorito MC, Riccobene R, Arsena R, Vaccaro F, Vadalà A, Nardi E, Cusimano P, Cerasola G. Endothelin-1 and F2-isoprostane relate to and predict renal dysfunction in hypertensive patients. Nephrol Dial Transplant 2009; 24: 497-503.

14 Pryor WA. Cigarette smoke radicals and the role of free radicals in chemical carcinogenicity. Environ Health Perspect 1997; 105: 875-882.
15 Kadiiska MB, Gladen BC, Baird DD, Germolec D, Graham LB, Parker CE, Nyska A, Wachsman JT, Ames BN, Basu S, Brot N, Fitzgerald GA, Floyd RA, George M, Heinecke JW, Hatch GE, Hensley K, Lawson JA, Marnett LJ, Morrow JD, Murray DM, Plastaras J, Roberts II LJ, Rokach J, Shigenaga MK, Sohal RS, Sun J, Tice RR, Van Thiel DH, Wellner D, Walter PB, Tomer KB, Mason RP, Barrett JC. Biomarkers of oxidative stress study. II. Are oxidation products of lipids, proteins, and DNA markers of $\mathrm{CC}_{14}$ poisoning? Free Radic Biol Med 2005; 38: 698-710.

16 Tsimikas S, Willerson JT, Ridker PM. C-reactive protein and other emerging blood biomarkers to optimize risk stratification of vulnerable patients. J Am Coll Cardiol 2006; 47: C19-C31.

17 Ross R. Atherosclerosis is an inflammatory disease. Am Heart J 1999; 138 (5 Pt 2): S419-S420.

18 Himeno M, Ishibashi T, Nakano S, Furuya K, Yoshida J, Kigoshi T, Uchida K, Nishio M. Implication of steady state concentrations of nitrite and nitrate metabolites of nitric oxide in plasma and whole blood in healthy human subjects. Clin Exp Pharmacol Physiol 2004; 31 (9): 591-596.

19 Matsuo S, Imai E, Horio M, Yasuda Y, Tomita K, Nitta K, Yamagata K, Tomino Y, Yokoyama $\mathrm{H}$, Hishida A. Collaborators developing the Japanese equation for estimated GFR. Revised equations for estimated GFR from serum creatinine in Japan. Am J Kidney Dis 2009. 53: 982-992.

20 Helmersson J, Basu S. F2-isoprostane excretion rate and diurnal variation in human urine. Prostaglandins Leukot Essent Fatty Acids 1999; 61: 203-205.

21 MacArthur PH, Shiva S, Gladwin MT. Measurement of circulating nitrite and S-nitrosothiols by reductive chemiluminescence. J Chromatogr B Analyt Technol Biomed Life Sci 2007; 851: 93-105.

22 Yang BK, Vivas EX, Reiter CD, Gladwin MT. Methodologies for the sensitive and specific measurement of s-nitrosothiols, iron-nitrosyls, and nitrite in biological samples. Free Rad Res 2003; 37: 1-10.

23 Field A. Discovering Statistics Using SPSS, 3rd edn. SAGE Publications: London, 2009, pp 191.

24 Mitaka C, Hirata Y, Yokoyama K, Wakimoto H, Hirokawa M, Nosaka T, Imai T. Relationships of circulating nitrite/nitrate levels to severity and multiple organ dysfunction syndrome in systemic inflammatory response syndrome. Shock2003; 19: 305-309.

25 Ghasemi A, Zahedi AS, Mehrabi Y, Saadat N, Azizi F. Serum nitric oxide metabolite levels in a general healthy population: relation to sex and age. Life Sci 2008; 83: 326-331.

26 Ishizaka N, Ishizaka Y, Toda E, Shimomura H, Koike K, Seki G, Nagai R, Yamakado M. Association between cigarette smoking and chronic kidney disease in Japanese men. Hypertens Res 2008; 31: 485-492.

27 Pawlik WW, Jacobson ED, Banks RO. Actions of nicotine on renal function in dogs. Proc Soc Exp Biol Med 1985; 178: 585-590.

28 Pinto-Sietsma SJ, Mulder J, Janssen WM, Hillege HL, de Zeeuw D, de Jong PE. Smoking is related to albuminuria and abnormal renal function in nondiabetic persons. Ann Intern Med 2000; 133: 585-591.

29 Hallan S, de Mutsert R, Carlsen S, Dekker FW, Aasarød K, Holmen J. Obesity, smoking, and physical inactivity as risk factors for CKD: are men more vulnerable? Am J Kidney Dis 2006; 47: 396-405.

30 Shankar A, Klein R, Klein BE. The association among smoking, heavy drinking, and chronic kidney disease. Am J Epidemiol 2006; 164: 263-271.

31 Chung FM, Yang YH, Shieh TY, Shin SJ, Tsai JC, Lee YJ. Effect of alcohol consumption on estimated glomerular filtration rate and creatinine clearance rate. Nephrol Dial Transplant 2006; 21: 819-820

32 Lippi G, Banfi G, Salvagno GL, Franchini M, Guidi GC. Glomerular filtration rate in endurance athletes. Clin J Sport Med 2008; 18: 286-288.

33 Lhotta K, Rumpelt HJ, König P, Mayer G, Kronenberg F. Cigarette smoking and vascular pathology in renal biopsies. Kidney Int/ 2002; 61: 648-654

34 Black HR, Zeevi GR, Silten RM, Walker Smith GJ. Effect of heavy cigarette smoking on renal and myocardial arterioles. Nephron 1983; 34: 173-179.

35 Barbieri SS, Weksler BB. Tobacco smoke cooperates with interleukin-1beta to alter beta-catenin trafficking in vascular endothelium resulting in increased permeability and induction of cyclooxygenase-2 expression in vitro and in vivo. FASEB J 2007; 1: 1831-1843.

36 Pinto-Sietsma SJ, Janssen WM, Hillege HL, Navis G, de Zeeuw D, de Jong PE. Urinary albumin excretion is associated with renal function abnormalities in a non-diabetic population. J Am Soc Nephrol 2000; 11 (10): 1882-1888.

37 Zhang WZ, Venardos K, Chin-Dusting J, Kaye DM. Adverse effects of cigarette smoke on NO bioavailability: role of arginine metabolism and oxidative stress. Hypertension 2006: 48: 278-285.

38 Ota Y, Kugiyama K, Sugiyama S, Ohgushi M, Matsumura T, Doi H, Ogata N, Oka H, Yasue $\mathrm{H}$. Impairment of endothelium-dependent relaxation of rabbit aortas by cigarette smoke extract-role of free radicals and attenuation by captopril. Atherosclerosis 1997: 131: 195-202.

39 Guo X, Oldham MJ, Kleinman MT, Phalen RF, Kassab GS. Effect of cigarette smoking on nitric oxide, structural, and mechanical properties of mouse arteries. Am J Physiol Heart Circ Physiol 2006; 291: H2354-H2361.

40 Barua RS, Ambrose JA, Eales-Reynolds LJ, DeVoe MC, Zervas JG, Saha DC. Dysfunctional endothelial nitric oxide biosynthesis in healthy smokers with impaired endothelium-dependent vasodilatation. Circulation 2001; 104: 1905-1910.

41 Kielstein JT, Peter C, Adams MC. Cigarettes and ADMA: the smoke hasn't cleared yet (letter). Hypertension 2006; 48: E20.

42 Eid HM, Arnesen H, Hjerkinn EM, Lyberg T, Seljeflot I. Relationship between obesity, smoking, and the endogenous nitric oxide synthase inhibitor, asymmetric dimethylarginine. Metabolism 2004; 53: 1574-1579. 
43 Rångemark C, Wennmalm A. Smoke-derived nitric oxide and vascular prostacyclin are unable to counteract the platelet effect of increased thromboxane formation in healthy female smokers. Clin Physiol 1996; 16: 301-315.

44 Morrow JD, Frei B, Longmire AW, Gaziano JM, Lynch SM, Shyr Y, Strauss WE, Oates JA, Roberts LJ. Increase in circulating products of lipid peroxidation ( $\mathrm{F}_{2}$-isoprostanes) in smokers: smoking as a cause of oxidative damage. N Engl J Med 1995; 332. 1198-1203.
45 Comporti M, Signorini C, Arezzini B, Vecchio D, Monaco B, Gardi C. F2-isoprostanes are not just markers of oxidative stress. Free Radic Biol Med 2008; 44: 247-256.

46 Bermudez EA, Rifai N, Buring JE, Manson JE, Ridker PM. Relation between markers of systemic vascular inflammation and smoking in women. Am J Cardiol 2002; 89: 1117-1119.

47 Paisley KE, Beaman M, Tooke JE, Mohamed-Ali V, Lowe GD, Shore AC. Endothelial dysfunction and inflammation in asymptomatic proteinuria. Kidney Int 2003; 63 : 624-633. 